\title{
Reexamining staggered boards and shareholder value
}

\section{Citation}

Cohen, Alma, and Charles C.Y. Wang. 2017. "Reexamining Staggered Boards and Shareholder Value." Journal of Financial Economics (June). doi:10.1016/j.jfineco.2017.06.004.

\section{Permanent link}

http://nrs.harvard.edu/urn-3:HUL.InstRepos:33785677

\section{Terms of Use}

This article was downloaded from Harvard University's DASH repository, and is made available under the terms and conditions applicable to Open Access Policy Articles, as set forth at http:// nrs.harvard.edu/urn-3:HUL.InstRepos:dash.current.terms-of-use\#OAP

\section{Share Your Story}

The Harvard community has made this article openly available.

Please share how this access benefits you. Submit a story.

\section{Accessibility}


ISSN 1936-5349 (print)

ISSN 1936-5357 (online)

\title{
HARVARD
}

JOHN M. OLIN CENTER FOR LAW, ECONOMICS, AND BUSINESS

\section{REEXAMINING STAGGERED BOARDS AND SHAREHOLDER VALUE}

\author{
Alma Cohen and Charles C. Y. Wang
}

Discussion Paper No. 908

$06 / 2017$

Harvard Law School

Cambridge, MA 02138

This paper can be downloaded without charge from:

The Harvard John M. Olin Discussion Paper Series: http://www.law.harvard.edu/programs/olin_center/

The Social Science Research Network Electronic Paper Collection: https://papers.ssrn.com/abstract=2985152

This paper is also Discussion Paper 2017-10 of the Harvard Law School Program on Corporate Governance 


\title{
Reexamining staggered boards and shareholder value*
}

\author{
Alma Cohen $^{\mathrm{a}, \mathrm{b}, \mathrm{c}}$ and Charles C. Y. Wang ${ }^{\mathrm{d}}$
}

\begin{abstract}
Cohen and Wang (2013) (CW2013) provide evidence consistent with market participants perceiving staggered boards to be value reducing. Amihud and Stoyanov (2016) (AS2016) contests these findings, reporting some specifications under which the results are not statistically significant. We show that the results retain their significance under a wide array of robustness tests that address the concerns expressed by AS2016. Our empirical findings reinforce the conclusions of CW2013.
\end{abstract}

Keywords: Corporate governance; Staggered boards; Takeover defense; Antitakeover provisions; Firm value; Delaware; Airgas.

JEL classification: G30, G34, K22

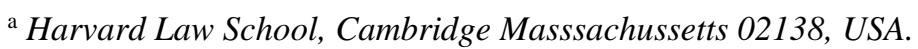

${ }^{\mathrm{b}}$ National Bureau of Economic Research, 1050 Massachusetts Ave., Cambridge, Massachusetts 02138, USA.

' Tel Aviv University Berglas School of Economics, Tel Aviv, Israel.

${ }^{\mathrm{d}}$ Harvard Business School, Boston, Massachussetts 02163, USA.

*We would like to thank an anonymous referee, Lucian Bebchuk, and Paul Healy for helpful suggestions. We also thank Kyle Thomas, Raaj Zutshi, Peter Simms, and Sophie Wylen for excellent research assistance. 


\section{Introduction}

In a paper published in the Journal of Financial Economics in 2013, "How do staggered boards affect shareholder value? Evidence from a natural experiment”, Cohen and Wang (2013; CW2013), we provide evidence that market participants perceive staggered boards to be, on average, value-reducing. ${ }^{1}$ Amihud and Stoyanov (2016; AS2016) contests our findings, arguing that excluding some observations or amending some specifications renders our results not statistically significant (though they largely retain their sign). In this paper, we carry out empirical tests that address the concerns of AS2016, and we show that the evidence is overall consistent with the conclusions of CW2013.

CW2013 reports that the two rulings by the Delaware courts in Air Products \& Chemicals Inc. v. Airgas, Inc. are accompanied by abnormal stock returns that are statistically significant and consistent with the view that staggered boards are value-decreasing. With the exception of its replication of the CW2013 specifications, AS2016 does not present results that are statistically significant, and the results based on our sample largely have a sign consistent with the conclusions of CW2013. Thus, these results are not by themselves inconsistent with the view that staggered boards are value-decreasing.

In any event, our comprehensive analysis of the stock returns accompanying the Airgas case indicates that the evidence is overall consistent with the view that staggered boards are value-

\footnotetext{
${ }^{1}$ Our results are consistent with some recent event studies (e.g., Cunat, Gine, and Guadalupe, 2012; Kim, 2015; and earlier Daines, 2001) providing evidence that staggered boards, and board insulation more generally, are perceived by market participants to decrease firm value. Relatedly, recent event study evidence offers mixed views on whether proxy-access reforms have positive or negative effects (e.g., Becker, Subramanian, and Bergstresser, 2013; Larcker, Ormazabal, and Taylor, 2011; Cohn, Gillan, and Hartzell, 2016), but it is not clear whether such reforms would have material impact on board insulation.

It is worth stressing, as we did in CW2013 (p. 628), that our work (and the other event studies cited above that find negative effects of staggered boards) estimates the average treatment effect (of weakening staggered boards) for the affected firms in the sample. Thus, this work cannot rule out the possibility that market participants view staggered boards as having heterogeneous effects.
} 
decreasing. When an event study is not based on a large number of observations, the statistical significance of its results is often sensitive to the removal of a small number of observations. However, in the case of our study, our results retain their significance under a wide range of tests conducted to address the concerns raised by AS2016.

The remainder of this paper is organized as follows. Section 2 describes the results of CW2013 and the analysis of AS2016. Given the concerns regarding robustness raised by AS2016, Section 2 also discusses two alternative definitions of treated companies to improve robustness by expanding the sets of treated firms to include firms that are affected less strongly by the rulings. We show that these specifications yield conclusions that are consistent with CW2013.

Section 3 focuses on the central issue raised by AS2016, that is, the results of CW2013 become statistically insignificant when excluding a handful of very small companies and, thus, cannot inform the assessment of how staggered boards affect value in normal-size firms. We first show that, when imposing the same sample filters recommended by AS2016, the results are statistically significant using the two alternative definitions of treated firms. We then demonstrate that, using all three treatment definitions, the results of CW2013 are robust to excluding all companies with market capitalization below $\$ 500$ million or $\$ 1$ billion instead of excluding the handful of small firms suggested by AS2016. These findings are inconsistent with the claim that the CW2013 results are driven by small companies and that they do not hold when such firms are excluded.

Turning to examine the source of the nonsignificance results presented in AS2016, we show that they are not due to a differential size effect. Instead, these results are due to the happenstance that some of the firms excluded by AS2016 have large returns that go in one direction; that is, the sample restrictions of AS2016 happen to remove extreme observations 
asymmetrically, from one side of the return distribution. After excluding large returns symmetrically from both sides of the distribution, we obtain an array of results (across various alternative specifications and samples excluding small firms) that are consistent with the results and conclusions of CW2013.

Section 4 examines the AS2016 claim that the results of CW2013 are unduly driven by a few particular observations with extreme returns. We first show that, when excluding the observations suggested by AS2016, our results still retain their significance using the two alternative definitions of treatment firms. Furthermore, when excluding extreme returns in a symmetric fashion, we obtain results that are statistically significant and consistent with the conclusions of CW2013 under each of the three alternative definitions of treated firms.

Finally, Section 5 considers the sensitivity of the CW2013 results to our using industry fixed effects based on six-digit Global Industry Classicification Standard (GICS-6). AS2016 suggests using four-digit GICS (GICS-4), as opposed to GICS-6, and argues that doing so renders our results not statistically significant. We show that the results retain their significance even when using GICS-4 fixed effects under either of the two alternative definitions of treated firms. Furthermore, under each of the alternative treatment definitions, the results retain their significance when no industry fixed effects are used, as is common in event studies (e.g., Larcker, Ormazabal, and Taylor, 2011; Cunat, Gine, and Guadalupe, 2012; Becker, Subramanian and Bergstresser, 2013; Cohn, Gillan and Hartzel, 2016). ${ }^{2}$

Finally, we conclude in Section 6. Overall, the wide array of results from our reexamination of the data are consistent with and reinforce the conclusions of CW2013.

\footnotetext{
${ }^{2}$ Some additional points and results can be found in Cohen and Wang (2015), the earlier version of this paper.
} 


\section{Our results and the AS2016 critique}

In this Section, we provide an overview of CW2013 and its main findings and examine the robustness of the main findings to alternative specifications. We then review the AS2016 critique of the conclusions of CW2013.

\subsection{The identification strategy of CW2013}

Staggered boards are associated with lower firm value as measured by Tobin's q. ${ }^{3}$ Correlation, however, does not imply causation, and CW2013 sought to contribute to the literature by examining whether staggered boards lead to lower firm valuation.

This issue has policy significance. Shareholder support for annual elections has been substantial over the last 15 years. Major institutional shareholders and the leading proxy advisers have adopted policies in favor of de-staggering boards. In response to shareholders' expressed preferences, many companies have adopted a unitary board structure. The debate continues in the marketplace, however, as some issuers and their advisers continue to support staggered boards.

To study the effect of staggered boards on shareholder value, we took advantage of a quasiexperimental setting arising from two Delaware court rulings on the takeover battle between Airgas, Inc. (ARG) and Air Products \& Chemicals, Inc. These rulings addressed the permissibility of shareholder-adopted bylaw amendments that substantially weaken the antitakeover force of staggered boards at firms whose annual shareholder meetings take place late in the year but not at

\footnotetext{
${ }^{3}$ See, e.g., Bebchuk and Cohen (2005), Faleye (2007), Frakes (2007), and Bebchuk, Cohen, and Ferrell (2009). Some studies show that staggered boards are associated with more agency problems or worse corporate decision making (e.g., Masulis, Wang, and Xie, 2007), but other studies (e.g., Johnson, Karpoff, and Yi, 2015) suggest that staggered boards are associated with some positive effects.

As to board-insulating arrangements in general, a body of work suggests that weaker shareholder rights and more insulated boards are associated with lower value (e.g., Gompers, Ishii, and Metrick, 2003) and with greater agency problems and worse corporate decision making (e.g., Dittmar and Mahrt-Smith, 2007; Harford, Mansi, and Maxwell, 2008; Harford, Humphrey, Powell, 2012).
} 
firms whose meetings take place early in the year. In the initial ruling, issued on October 8, 2010, the Delaware Chancery Court said that such shareholder-adopted bylaw amendments are permissible. On November 23, 2010, however, the Delaware Supreme Court reversed the lowercourt ruling and held such amendments to be invalid. Our identification strategy relies on the assumption that both rulings were at least partly unanticipated.

To construct our sample, we collected governance data from the Factset SharkRepellent database - specifically, data on annual meeting dates and the presence of staggered boards-for the cross section of firms classified as trading on a primary exchange. We limited our analyses to the subsample of firms for which we were able to find a match to a historical Center for Research in Security Prices (CRSP) permno identifier and Compustat gvkey identifier. We excluded REITs, firms with dual-class shares, and firms with majority insider ownership.

Because we began our analysis for CW2013 shortly after the two rulings, stock returns were at the time unavailable from CRSP. We therefore merged returns data obtained from Datastream with our SharkRepellent sample. Moreover, as Fama and French factors' returns for the dates around the rulings were also unavailable at the time, we employed an alternative method for inferring excess returns that did not rely on factors' returns data during this period. We computed risk-adjusted excess returns in two steps (see pp. 633-634 of CW2013 for a detailed description). The first step was the standard procedure for estimating each firm's factor loadings on the Fama and French three factors and the momentum factor, using the most recently available 120 trading days' data ending on or prior to June 30, 2010 (for which factor returns were available). In the second step, we obtained excess announcement-window returns by taking the residuals from a cross-sectional regression of the raw announcement-window returns on the estimated factor 
sensitivities, in which our cross-sectional data included all the firms in our SharkRepellentDatastream intersection.

Our empirical analysis focused on the differences in excess announcement returns between firms with staggered boards that can be expected to be most affected by the rulings (Delaware firms with a staggered board and an annual meeting held late in the year, from September to December), and firms with staggered boards that were expected to be least affected by the rulings (Delaware firms with a staggered board and an annual meeting held early in the year, from January to March). Both types of firms hold their annual meetings off-season, either after or before the April-to-June period during which most firms hold their annual meetings. Using this definition of treated firms, which we label Treat-1, the sample considered by CW2013 consisted of 77 firms classified as treated and 62 classified as controls.

We focused our analyses on comparing early- and late-meeting firms with staggered boards because, as we argued in CW2013 (p. 633), firms with and without staggered boards could differ substantially along several dimensions. Comparing staggered with non-staggered firms could obfuscate inferences from observed differences in announcement-period returns (for example, if other news on the same day affected some firm types that are correlated with the choice of staggered boards). In other words, our identification strategy assumed that the treatment status, whether a firm in an industry is early- or late-meeting, is practically as good as random or at least unconfounded (see p. 634 and footnote 22 of CW2013 for a detailed discussion of our identification strategy). In this connection, the early- and late-meeting firms are similar in that both types hold meetings off-season and the meeting-date classification is predetermined.

Table 1, Column 1 of Panel A presents the main result of CW2013. Observations from both events are integrated in a single regression by multiplying the excess returns around the second 
ruling by -1 . We include GICS-6 industry fixed effects to account for the possibility of industryspecific news that confounds our analyses. We then estimate a pooled regression of the two-day excess returns (in basis points) on a treatment group indicator (Treat) and an indicator for the second event date (Event-2). We find, as in Table 1, Column 2, of CW2013, differential abnormal announcement returns of 96.12 basis points, which is significant at the $10 \%$ level. $^{4}$

[Insert Table 1 here]

Panel B presents the results of the alternative method used by CW2013 for assessing the statistical significance of these results. We examine how common it is over a sample of nonevent days to observe treatment effects (i.e., differences in excess returns between late- and earlymeeting firms) that are large and positive on one day and large and negative on another. To facilitate this analysis, we simulate a bivariate distribution over pairs of nonevent days from January to June 2010 of treatment coefficients obtained from regressions of excess returns on the treatment indicator. Based on this simulated distribution, we conclude that it is unlikely, occurring less than $0.6 \%$ of the time, for both the first event date to produce a treatment coefficient of 83 basis points or higher and the second event date to produce a treatment coefficient of -109 basis points or lower. Thus, our simulation $p$-values suggest that the observed pair of coefficients is statistically significant at the $1 \%$ level.

\footnotetext{
${ }^{4}$ Although CW2013 explains the rationale for its use of two-day returns, AS2016 suggests using one-day returns instead without providing reasons for deviating from two-day returns. CW2013 explains that the timing of each of the rulings warrants using two-day returns. The first ruling took place after the close of the stock market on Friday, October 8, 2010. The first trading day following the ruling was thus Monday, October 11, which was Columbus Day. Because trading volumes on Columbus Day are lower than usual and because most of the substantive, in-depth media discussion of the Chancery Court ruling came out only on Monday, October 11, and Tuesday, October 12, CW2013 opted to use the two-trading-day window ending at the close of market on October 12. The second ruling was released during market trading hours, at 1:30 p.m. on November 23. It was difficult for market participants to digest the ruling and its import during the short two-and-a-half-hour window before the close of trading on that day. Therefore, CW2013 opted to use the two-trading-day window from the November 22 close to the November 24 close.
} 


\subsection{Robustness to alternative specifications}

Given the concerns regarding the robustness of our findings raised by AS2016, we would like at the outset to show the robustness of the results to two types of alternative specifications: an alternative estimation of risk-adjusted returns and alternative definitions of the set of treated companies.

\subsubsection{Risk-adjusted returns}

The method adopted in CW2013 for estimating risk-adjusted returns was dictated by the data available when we began our study. Using CRSP data that subsequently became available, AS2016 focuses on another method. This commonly used method, labeled Method 2 in AS2016 and below, infers expected daily stock returns to be the risk-free rate plus the inner product of the estimated factor sensitivities for a given stock and the event-date factor returns then cumulates the excess returns over the two-day event windows.

Reestimating our excess returns using the now-available data on factors' returns around the event dates, we found a correlation of 0.9906 between the excess returns obtained using Methods 1 and 2. Column 2 of Table 1 reruns the basic regression of CW2013 using the excess returns obtained from Method 2. The results are, unsurprisingly, nearly identical to those produced using Method 1. We also perform the simulation exercise using Method 2, and the results (see Table 1, Panel B) again produce findings that are practically identical in both magnitude and statistical significance to those reported in CW2013 using Method $1 .^{5}$

We agree that Method 2 is more commonly used. CW2013 used Method 1 only because the data required by Method 2 was not available when we began our work. Given that the two

\footnotetext{
${ }^{5}$ The results reported by AS2016 also confirm (see their Table 1, Rows 1 and 2) that the results obtained using Method 1 and Method 2 are practically identical.
} 
methods yield practically identical results, we use Method 2 in all the results reported in the remainder of this paper.

\subsubsection{Definition of treated companies}

To investigate the robustness of our results to the definition of treated firms, we use two alternative definitions with an expanded set of treated firms. Such expansion affects our tests in two different ways. On the one hand, given the small size of the sample of treated firms used in CW2013, increasing the sample can increase the statistical power of our tests. On the other hand, there could be a trade-off because the expansion of the sample is done by including firms that are likely to be affected less strongly by the rulings. Clearly, however, examining results under these alternative definitions provides a useful robustness check.

Under one alternative definition, which we label Treat-2, we add to the set of treated firms those firms whose meetings occur in July and August. Moving from Treat-1 to Treat-2 increases the sample of treated firms from 77 to 110 , an increase of nearly 50\%. Column 3 of Table 1 reruns the analysis of Column 2 using Treat-2. With the increase in the number of treated firms, the size of the Treat coefficient does not change substantially while the statistical significance increases to the $1 \%$ level, using either conventional or simulation $p$-values.

The other definition of treated firms, which we label Treat-3, is a refinement of Treat- 2 . Under Delaware law, a board of directors can delay an annual meeting as long as it does not take place more than 13 months after the date of the prior annual meeting. Thus, the board of directors of a firm whose annual meeting takes place in December could shift to a January meeting date with relative ease, merely by holding the next annual meeting in January. By contrast, late-meeting firms with a meeting date prior to December cannot easily switch to an early-meeting date. Therefore, it could be argued that firms with December meeting dates can be expected to have 
been less affected by the Airgas rulings than firms with late-meeting dates prior to December. Treat-3 takes this issue into account by excluding firms with a December annual meeting and defining treated firms as those with meeting dates between June and November.

Compared with Treat-1, moving to Treat-3 increases the sample of treated firms from 77 to 97 , an increase of about $26 \%$. Although the increase in sample size using Treat-3 is smaller than the increase using Treat-2, using Treat-3 has the potential advantage of eliminating Decembermeeting firms that are likely to be less affected by the ruling and thus enabling a sharper identification. Column 4 reruns the specification of Column 2 using Treat-3. With the exclusion of firms likely to be little affected, the coefficient on the treatment indicator increases in magnitude by about $25 \%$ (to about 120 basis points) and is, as in Column 3, significant at the $1 \%$ level using either conventional or simulation $p$-values.

\subsection{The AS2016 critique}

AS2016 questions the conclusions of CW2013 by presenting amendments to our regressions that weaken or eliminate the statistical significance of our results. We examine these issues in detail in Sections 3-5. We show that, even accepting the validity of concerns raised by AS2016, our results remain significant under a wide range of reasonable specifications.

The main argument of AS2016, and its key claims regarding the effects of removing economically insignificant companies or particular outlier observations, is based on an analysis of our sample, which is derived from the large SharkRepellent data set. AS2016 further supports their analysis by producing nonsignificant results using a sample based on the smaller ISS (formerly RiskMetrics) data set. AS2016 notes that using the ISS sample reduces the number of treated firms by about $60 \%$ (from 77 to 31 ) but justifies this analysis on the grounds that it uses an "alternative 
sample." However, the ISS sample is not an alternative sample but a subset of the SharkRepellent sample. ${ }^{6}$

Although an analysis of a subset could be useful, in our view the construction of such a subset should be based on a relevant economic criterion, not by reference to the availability of data supplied by another provider. Given that the ISS data set contains firms with a larger average market capitalization, we analyze, in addition to the entire SharkRepellent sample used in CW2013, subsets of it based on market capitalization. We examine subsets of companies with a market capitalization exceeding $\$ 500$ million and $\$ 1$ billion.

In analyzing our sample, AS2016 reports results using the Treat-1 definition of treated firms but not the Treat-2 or Treat-3 definitions. In analyzing the smaller ISS sample, AS2016 does use Treat-2 for one of its tests (see test S1.1, discussed in AS2016, p. 15). However, when providing its key results regarding our sample, AS2016 does not report results using Treat-2 or Treat-3. When the specifications that AS2016 applies to our sample using Treat-2 and Treat-3 are rerun, the results are generally statistically significant and consistent with CW2013.

Also, AS2016 does not provide results assessing the significance of our results over two event dates using the simulation method (see Table 1, Panel B), which was used throughout CW2013. Most of the tests reported by AS2016 yield significant coefficients that are consistent with the conclusions of CW2013 when simulation $p$-values are used to assess the significance of observed coefficients.

\footnotetext{
${ }^{6}$ In our examination of the 2010 vintage of the ISS data set, all the treated and control companies that we were able to identify were already included in the set of treated and control companies in our SharkRepellent sample.
} 


\section{Excluding small firms}

AS2016 (p. 433) argues that the conclusions of CW2013 cannot "confidently advise exchange-listed firms with normal size and stock price that their value is affected by having a staggered board." To support this argument, AS2016 reports that the results of CW2013 lose their statistical significance when excluding a handful of "insignificant" firms. We show that this nonsignificance finding depends on the use of very particular specifications and that amending them in reasonable ways yields a wide array of results that are significant and consistent with the findings of CW2013. Our results are strengthened in the tests below that focus on firms of a meaningful size.

Instead of examining the consequences of excluding the many small firms in our sample, AS2016 reports only the results of specifications based on excluding a handful of firms. AS2016 focuses on three sets of firms: (1) six stocks with market capitalization below \$10 million (called "micro-cap firms" in AS2016), (2) three stocks that are not exchange-listed over-the-counter (OTC) firms and therefore do not have CRSP returns (which are not available for OTC firms), and (3) five stocks with share prices below $\$ 1$ (penny stocks). These categories are largely overlapping. Most of the OTC firms in subset (2) and most of the penny-stock firms in subset (3) have a market capitalization below $\$ 10$ million. Moreover, even OTC and penny-stock observations with a market capitalization exceeding $\$ 10$ million are small.

Table 2, Row 1, reruns the results of Table 1, Column 2, using Treat-1 for the definition of treated firms and excluding firms below the $\$ 10$ million market cap. ${ }^{7}$ We report a coefficient on the treatment indicator of about 47 basis points that is statistically insignificant at the conventional levels. This finding replicates AS2016, which reports a coefficient of about 48 basis points that is

\footnotetext{
${ }^{7}$ We measure market capitalization on the last trading day of the calendar month prior to each event.
} 
statistically insignificant at conventional levels. However, while the coefficient of Treat-1 in Table 2 is not significant using conventional $p$-values, the simulation $p$-values suggest that the observed pair of coefficients is significant at the $10 \%$ level.

\section{[Insert Table 2 here]}

Rows 2 and 3 rerun the specification of Row 1 using Treat- 2 and Treat-3, respectively. With more observations enabled by these two definitions, and with the sharper identification enabled by Treat-3, the coefficient on the treatment indicator is about 66 and 74 basis points, respectively, both significant at the 5\% level, using either conventional or simulation $p$-values.

AS2016 (pp. 7 and 13) suggests that its proposed sample filters aim at excluding "small" or "very small" stocks. However, though the $\$ 10$ million threshold used by AS2016 excludes a handful of specific observations that we show to have certain one-sided characteristics, a substantial number of micro-cap firms with very small market capitalizations are left in the sample. To directly investigate the AS2016 hypothesis that staggered boards are not perceived by market participants to have an effect on shareholder value when small firms are excluded, we examine specifications that focus on the subset of firms whose market capitalization exceeds more meaningful thresholds of $\$ 500$ million and $\$ 1$ billion. Using these thresholds eliminates all microcap companies as well as all OTC and penny-stock firms from our sample. We find that the CW2013 results are robust to, and seem to be stronger in, using subsets of firms exceeding the $\$ 500$ million or $\$ 1$ billion thresholds.

Rows 4-6 of Table 2 rerun the results using Treat-1, Treat-2, and Treat-3, respectively, by excluding all firms with a market capitalization below $\$ 500$ million. This criterion reduces the size of the initial samples by about $46 \%-50 \%$, depending on the definition of treated firms used. In each of the three specifications, the coefficient on the treatment indicator is significant at the $10 \%$ 
level or lower, using either conventional or simulation $p$-values. Moreover, the magnitudes of the coefficients are consistently larger relative to the specifications in Rows $1-3$, which exclude only the smallest firms with a market capitalization below \$10 million.

Rows 7-9 rerun the results using Treat-1, Treat-2, and Treat-3, respectively, by excluding all firms with a market capitalization below $\$ 1$ billion. With this filter, the initial sample is reduced by about $63 \%-65 \%$, depending on the definition of treated firms used. However, the results in each of the three specifications are still significant at the 5\% level or lower, using either conventional or simulation $p$-values. Again, the magnitudes of the coefficients are consistently larger than those in Rows 1-3 and Rows 4-6, which exclude fewer small firms.

The results in Rows 4-9 are inconsistent with the AS2016 claim that the results of CW2013 do not hold when small firms are excluded. What then explains the results of AS2016? When examining the small and overlapping sets of firms with market capitalization below $\$ 10$ million, OTC firms, and penny-stock firms, we find that these sets of firms include some observations with large returns that operate in the direction of the conclusions of CW2013 but do not include observations with large returns that operate in the opposite direction.

Whereas Rows 4-9 address the AS2016 concern that our results are driven by very small stocks, could the AS2016 analysis cast doubt on the CW2013 results by suggesting that they are driven by a few outliers? Below we address this concern by using an exclusion criterion that is symmetric and removes outliers on both sides of the distribution.

Rows 10-12 rerun the specifications of Rows 1-3, which exclude firms with a market capitalization below $\$ 10$ million and use Treat-1, Treat-2, and Treat-3, respectively, but also exclude observations that belong to the top and bottom $1 \%$ of the treatment firm and control firm 
return distributions, respectively, on each event date. ${ }^{8}$ With outliers removed from both sides of the distribution in this way, the coefficient on the treatment indicator is now significant at the $10 \%$ level or lower in all three rows, using either conventional or simulation $p$-values. The coefficient on Treat- 1 is significant at the $10 \%(5 \%)$ level using conventional (simulation) $p$-values, and the coefficients on Treat-2 and Treat-3 are significant at the 5\% level using both types of $p$-values. Thus, when outlier observations in both directions are removed, the results are significant both in the Treat-1 specification that AS2016 uses and in alternative specifications.

Rows 13-15 rerun the specifications of Rows 1-3, but this time, in addition to excluding firms with a market capitalization below $\$ 10$ million, OTC firms, penny-stock firms, and observations in the top or bottom $1 \%$ of the return distribution are excluded. ${ }^{9}$ Again, the coefficient on Treat 1 is significant at the $10 \%(5 \%)$ level using conventional (simulation) $p$-values, and the coefficients on Treat-2 and Treat-3 are significant at the 5\% level or lower using both types of $p$ values.

In Rows 16-18, we rerun the three specifications of Rows 13-15 using market capitalization thresholds of $\$ 500$ million, instead of $\$ 10$ million, in addition to excluding observations in the top or bottom $1 \%$ of the return distribution. In each of the three specifications, the coefficient on the treatment indicator is positive and significant at the $10 \%$ level using conventional $p$-values. Furthermore, in each of these specifications, the treatment coefficient is significant at the $5 \%$ level or lower using simulation $p$-values.

\footnotetext{
${ }^{8}$ Because our empirical results compare the average returns of treatment firms with the average returns of control firms, we truncate the treatment and control distributions separately to assess the robustness of the respective averages to outliers. However, excluding observations at the top and bottom $1 \%$ of the pooled return distribution on each event yields similar results.

${ }^{9}$ One of the firms in our sample AdvanSource Biomaterials Corporation (ASB) is exchange-listed at the time of the first event but an OTC firm at the time of the second event. In the above specification, we exclude this firm from the sample altogether, but the results are essentially the same when we include it in the first event but not the second event.
} 
Similarly, Rows 19-21 rerun the specifications of Rows 13-15 using the market capitalization threshold of $\$ 1$ billion, instead of $\$ 10$ million, in addition to excluding observations in the top or bottom $1 \%$ of the return distribution. In all three specifications, the coefficient on the treatment indicator is positive and significant at the 5\% level using conventional $p$-values. Furthermore, in each of these three specifications, the results of the simulation are significant at the $1 \%$ level.

In sum, our analyses indicate that the conclusions of CW2013 are not driven by a handful of very small firms. The CW2013 finding that markets view staggered boards to be on average value-decreasing holds when focusing on the subsamples that exclude firms with market capitalization below $\$ 500$ million or $\$ 1$ billion. The empirical filters and results that AS2016 relies upon are therefore not driven by a differential size effect but by the happenstance that the small set of firms excluded by AS2016 contains firms with extreme observations from one side of the distribution. When outliers are excluded in a symmetric fashion, i.e., from both sides of the treatment and control event returns distribution, the results are robustly significant and consistent with the findings of CW2013.

\section{Excluding particular observations}

AS2016 also calls for the exclusion of particular observations from the analysis of CW2013. This section examines three concerns that AS2016 raises to justify excluding certain observations. Our event study consists of a small number of treated firms, and, in such a smallscale study, the statistical significance of results could be eliminated by excluding a small number of observations. However, the analysis shows that addressing these three particular concerns 
produces results that continue to be consistent with the conclusions of CW2013. Table 3 displays all of our results.

[Insert Table 3 here]

\subsection{Firms that received merger and acquisition $(M \& A)$ offers}

AS2016 remove two firms, Diamond Management (DTPI) and ArcSight (ARST), identified as having received an M\&A offer prior to the court rulings. The argument for doing so is that, had the acquisition been expected to be completed with absolute certainty, the stock prices of these companies would not have been affected by the court rulings. However, acquisition offers do not always result in an acquisition, and the value of the current governance provisions could thus be relevant even when an offer is outstanding. Furthermore, studies that examine the effects of staggered boards commonly do not attempt to remove from the samples firms that had an outstanding M\&A offer at the time that value was measured. Thus, the merits of removing these two firms are debatable.

Nonetheless, Rows 1, 2, and 3 of Table 3 rerun the regressions of Table 1, Columns 2, 3,

and 4 - that is, using the alternative definitions of treated firms Treat-1, Treat-2, and Treat-3-but exclude these two firms. The results are practically identical to those in Table 1 and are all statistically significant (to the same extent as in Table 1) and consistent with the conclusions of CW2013. Given that the results are practically identical with and without the two firms, we retain them in subsequent tests but verify that all the results are the same when excluding them.

\subsection{Observation with extreme returns}

In any event study, it is likely that an analysis of all media items and Securities and Exchange Commission (SEC) filings would identify firms whose large event date returns are 
probably attributable to idiosyncratic news instead of to the treatment that is the focus of the study. Researchers, however, often do not conduct such an analysis, relying on the premise that various idiosyncratic news items wash out and that the remaining signal reflects the market's response to the treatment under consideration. Following standard practice, CW2013 did not search for and exclude outliers, but we show that our results are robust to doing so.

AS2016 raises a concern about outliers by suggesting the exclusion from our analysis of the return (-40\%) accompanying the second event of one firm, AdvanSource Biomaterials (ASB), was largely due to an idiosyncratic effect. Row 4 of Table 3 largely replicates the result that AS2016 reports. Following AS2016 in using Treat-1 for the definition of treated firms and excluding ASB from the sample, we obtain a $t$-statistic of 1.58 , which falls below the conventional thresholds for statistical significance. ${ }^{10}$ Rows 5 and 6 report results using the Treat-2 and Treat-3 definitions of treated firms. The results are significant at the $1 \%$ or $5 \%$ levels, using either the conventional or simulation $p$-values.

More important, as we argue in Subsection 4.2, engaging in the exercise of identifying observations with large returns due to idiosyncratic shock should not focus only on large returns in one direction. To highlight the problem with excluding ASB alone, note that, whereas ASB had a large negative return on November 24, eOn Communications Corporation (EONC), which had the largest positive return during the second event window, had a return of $15 \%$, which was also unlikely to have been produced by the rulings.

Rows 7-9 rerun the basic results of Table 1 excluding both ASB and EONC. When an extreme observation is thus removed from each side of the return distribution, the baseline result

\footnotetext{
${ }^{10}$ We obtain practically identical results if we exclude the two M\&A observations (as AS2016 does) and do not exclude ASB altogether but exclude only (as AS2016 does) ASB's second-event-date return but retain its first-eventdate return.
} 
using Treat- 1 is significant at the $10 \%$ level using conventional $p$-values and at the $1 \%$ level using simulation $p$-values, consistent with CW2013. Moreover, running such a specification using the Treat-2 and Treat-3 definitions, we obtain significant results at the $1 \%$ level using either the conventional or simulation $p$-values.

Proceeding in a more systematic fashion following our approach in Subsection 4.2, Rows 10-12, using Treat-1, Treat-2, and Treat-3, respectively, exclude not only ASB but also all observations in each treatment and control sample that fall within the top and bottom $1 \%$ of returns on each event date. The results are significant at the 5\% level or lower in each of the three regressions, using either the conventional or simulation $p$-values. Thus, addressing objections about observations with extreme returns in a systematic and symmetric fashion leads to an increase, not a decrease, in the significance of our results.

\subsection{Firms that had an outstanding hostile tender offer}

Another observation that AS2016 suggests removing is Airgas, the company whose outstanding tender offer was the subject of the court ruling and whose stock return was significantly positive in the first event and significantly negative in the second event. The argument for removing this observation is that it is affected by the rulings through the general effect of a staggered board outside the context of a specific takeover situation as well as through a direct effect on the company's specific takeover situation. However, such a direct effect is part of the overall effect of staggered boards, and prior studies have commonly not attempted to eliminate from the sample firms that had an outstanding hostile offer at the time value was measured. In any event, although the claim that ARG should be excluded is debatable, we show that such exclusion does not undermine our results. 
Rows 13-16 report the results of rerunning our tests but excluding ARG. Row 13 replicates the results of AS2016, which reports results using only the Treat-1 definition of treated firms when excluding ARG. In Row 13, the $t$-statistic on Treat-1 is 1.59 and thus falls somewhat below conventional levels of statistical significance. However, the simulation $p$-values indicate that the coefficients are significant at the 5\% level. Furthermore, when excluding ARG and using Treat-2 and Treat-3, the results are significant at the 5\% level or lower using either the conventional approach or simulation $p$-values.

Rows 16-18 rerun the specifications of Rows 13-16 excluding not only ARG but also all the observations in the top and bottom $1 \%$ of the distribution as done previously. In each of the three specifications, the results are significant at the $10 \%$ level or lower using conventional $p$ values and at the $1 \%$ level using simulation $p$-values.

Overall, addressing concerns about outliers in a systematic and two-sided way highlights the robustness of our findings. The wide array of results in Table 3 reinforces the conclusions of CW2013.

\section{Industry fixed effects}

Event studies commonly do not include industry fixed effects (e.g., Larcker, Ormazabal, and Taylor, 2011; Cunat, Gine, and Guadalupe, 2012; Becker, Subramanian and Bergstresser, 2013; Cohn, Gillan and Hartzel, 2016). Though CW2013 reports results without including industry fixed effects, both it and our analysis above take the extra step of including industry fixed effects, using GICS-6 industry definitions, to account for the possibility of correlated industry news. AS2016 questions our use of GICS-6 and advocates using GICS-4 instead. We analyze the issue and show that our results are robust to using alternative specifications not based on GICS-6. 
The use of GICS-6 has been shown to outperform alternative industry classification schemes in explaining return co-movement (Bhojraj, Lee, and Oler, 2003; and Chan, Lakonishok, and Swaminathan, 2007). Though some of our observations lack industry peers using GICS-6, this does not distort our results. They are essentially eliminated from the estimation, thus only making it more difficult to obtain significance. Furthermore, when using GICS-4 as advocated by AS2016, seven firms in the treated or control groups still lack industry peers. While we view the use of GICS-6 to be reasonable, we examine alternative specifications.

Table 4 reports the results of 12 regressions performed to determine the extent to which our results are due to the use of GICS-6. As before, we conduct our tests for each of the three alternative definitions of treated firms. Rows 1-3 report results using GICS-4 industry fixed effects for Treat-1, Treat-2, and Treat-3, respectively.

\section{[Insert Table 4 here]}

In Row 1, consistent with the results reported by AS2016, the coefficient of Treated has a positive sign but is not significant at the conventional levels with a $t$-statistic of 1.3. However, the simulation $p$-values are significant at the 5\% level. Furthermore, under the two alternative definitions of the treated firms (Rows 2 and 3), using GICS-4 fixed effects produces treatment coefficients that are positive and statistically significant at conventional levels using either conventional or simulation $p$-values.

Next, Rows 4-6 of Table 4 rerun the specifications of Rows 1-3 but without any industry fixed effects. Whereas CW2013 includes fixed effects to account for the possibility of correlated industry news, the concerns regarding their use makes it worthwhile to conduct our analysis under the common approach of excluding industry fixed effects. As Rows 4-6 show, the results remain 
positive and statistically significant in each of the three specifications, using either the conventional approach or simulation $p$-values.

Rows 7-9 and 10-12 replicate the specifications of Rows 1-3 and 4-6 respectively, but this time excluding outliers in the return distribution as done in Tables 2 and 3. In Row 7, as in Row 1 , the treatment coefficient is positive and not significant using conventional $p$-values, but positive and significant using simulation $p$-values. In each of the subsequent five Rows, the treatment coefficient is positive and significant, using either conventional or simulation $p$-values, at the $5 \%$ level or $1 \%$ level. Thus, overall, the results of Table 4 are consistent with the conclusions of CW2013.

\section{Conclusion}

This paper examines the AS2016 critique of the CW2013 results, conducting many tests to address the robustness concerns that AS2016 raises. Our empirical analysis of the returns accompanying the Airgas rulings has yielded a wide array of statistically significant results that are consistent with and reinforce the conclusions of CW2013. Overall, the evidence is consistent with the view that market participants assess staggered boards to be on average value-reducing. 


\section{References}

Amihud, Y., Stoyanov, S., 2016. Do staggered boards harm shareholders? Journal of Financial Economics, 123 (2), 432-439.

Bebchuk, L., Cohen, A., 2005. The costs of entrenched boards. Journal of Financial Economics 78 (2), 409-433.

Bebchuk, L., Cohen, A., Ferrell, A., 2009. What matters in corporate governance? Review of Financial Studies 22 (2), 783-827.

Becker, B., Subramanian, G., Bergstresser, D., 2013. Does shareholder proxy access improve firm value? Evidence from the Business Roundtable challenge. Journal of Law and Economics 56, $127-160$.

Bhojraj, S., Lee, C., Oler, D., 2003. What's my line? A comparison of industry classification schemes for capital market research. Journal of Accounting Research 41 (5), 745-774.

Chan, L., Lakonishok, J., Swaminathan, B., 2007. Industry classifications and return comovement. Financial Analysts Journal 63 (6), 56-70.

Cohen, A., Wang, C., 2013. How do staggered boards affect shareholder value? Evidence from a natural experiment. Journal of Financial Economics 110 (3), 627-641.

Cohen, A., Wang, C., 2015. Staggered boards and shareholder value: a reply to Amihud and Stoyanov. Unpublished working paper. Harvard University, Cambridge, MA.

Cohn, J., Gillan, S., Hartzell, J., 2016. On enhancing shareholder control: a (Dodd-) Frank assessment of proxy access. Journal of Finance 71 (4), 1623-1668.

Cunat, V., Gine, M., Guadalupe, M., 2012. The vote is cast: the effect of corporate governance on shareholder value. Journal of Finance 67 (5), 1943-1977.

Daines, R., 2001. Do classified boards affect firm value? Takeover defenses after the poison pill. Unpublished working paper. Stanford University, Stanford, CA.

Dittmar, A., Mahrt-Smith, J., 2007. Corporate governance and the value of cash holdings. Journal of Financial Economics 83 (3), 599-634.

Faleye, O., 2007. Classified boards, firm value, and managerial entrenchment. Journal of Financial Economics 83 (2), 501-529.

Fama, E. F., French, K. R., 1993. Common risk factors in the return on stocks and bonds. Journal of Financial Economics, 33 (1), 3-56. 
Fama, E. F., French, K. R., 1996. Multifactor explanations of asset pricing anomalies. The Journal of Finance, 51 (1), 55-84.

Frakes, M., 2007. Classified boards and firm value. Delaware Journal of Corporate Law 32, 113157.

Gompers, P., Ishii, J., Metrick, A., 2003. Corporate governance and equity prices. Quarterly Journal of Economics 118 (1), 107-155.

Harford, J., Humphrey, M., Powell, R., 2012. The sources of value destruction in acquisitions by entrenched managers. Journal of Financial Economics 106 (2), 247-261.

Harford, J., Mansi, S., Maxwell, W., 2008. Corporate governance and firm cash holdings in the US. Journal of Financial Economics 87 (3), 535-555.

Johnson, W., Karpoff, J., Yi, S., 2015. The bonding hypothesis of takeover defenses: evidence from IPO firms. Journal of Financial Economics 117 (2), 307-332.

Kim, D., 2015. Board classification and shareholder value: evidence from corporate law amendments. Unpublished working paper. University of Texas, Austin, TX.

Larcker, D., Ormazabal, G., Taylor, D., 2011. The marker reaction to corporate governance regulation. Journal of Financial Economics 101 (2), 431-448.

Masulis, R., Wang, C., Xie, F., 2007. Corporate governance and acquirer returns. Journal of Finance 62 (4), 1851-1889. 


\section{Table 1}

Replicating and extending Cohen and Wang (2013).

Panel A reports the results from pooled ordinary least squares (OLS) regressions of two-day risk-adjusted ruling-announcement returns (pooling the October 8, 2010 and November 23, 2010 ruling returns) on a treatment firm indicator (Treat) and an indicator variable for the second event date (Event-2). The constant term (Cons) from the estimation is also reported. We pool the two events and multiply risk-adjusted returns on the second event date by -1 . Two methods for computing risk-adjusted returns are reported. Method 1, reported in Column 1, estimates risk-adjusted returns in two steps. First, each firm's loadings on the three factors of Fama and French (1993) on the up-minus-down (UMD) momentum factor of Fama and French (1996) are estimated using the most recently available 120 trading days' data ending on or prior to June 30,2010. Second, risk-adjusted announcement-window returns are obtained by taking the residuals from a cross-sectional regression of raw announcement window returns on the estimated factor sensitivities. Method 2, reported in Columns 2-4, infers expected daily stock returns to be the risk-free rate plus the inner product of the estimated factor sensitivities for a given stock and the event-date factor returns and cumulates the excess returns over the two-day event windows. Three alternative definitions of treatment firms are used. Treat- 1 takes a value of one for firms whose shareholder meetings take place between September and December, Treat-2 takes a value of one for firms whose shareholder meetings take place between July and December, and Treat-3 is identical to Treat-2 but excludes December-meeting firms. In all three definitions, control firms are those whose shareholder meetings take place between January and March. Six-digit Global Industry Classification Standard (GICS) fixed effects are included, and cluster-robust standard errors, clustered at the six-digit GICS level, appear immediately below the coefficient estimates in parentheses.

Panel B reports the ordinary least squares (OLS) coefficient on Treat for each event date and the likelihood of observing coefficients (simulated $p$-value) at least as large and positive as the observed Event- 1 coefficient and at least as large and negative as the observed Event-2 coefficient, using a simulated bivariate null distribution of coefficients generated from all unique pairs of nonevent trading dates from January 2 to June 30, 2010. Levels of significance are indicated by $*, * *$, and $* * *$, signifying $10 \%, 5 \%$, and $1 \%$, respectively.

\begin{tabular}{lcccc}
\hline \hline Panel A: Pooled & \multicolumn{2}{c}{ Method 1, } \\
& Treat-1 & $\begin{array}{c}\text { Method 2, } \\
\text { Treat-1 }\end{array}$ & $\begin{array}{c}\text { Method 2, } \\
\text { Treat-2 }\end{array}$ & $\begin{array}{c}\text { Method 2, } \\
\text { Treat-3 }\end{array}$ \\
\cline { 2 - 5 } Variable & $(1)$ & $(2)$ & $(3)$ & $(4)$ \\
\hline Treat & $96.116^{*}$ & $95.045^{*}$ & $97.249^{* * *}$ & $120.052^{* * *}$ \\
& $(51.34)$ & $(53.22)$ & $(31.22)$ & $(36.59)$ \\
Event-2 & 17.346 & 35.729 & 37.65 & 57.65 \\
& $(45.78)$ & $(45.20)$ & $(41.92)$ & $(47.45)$ \\
Cons & -42.535 & -48.182 & -47.387 & -51.972 \\
& $(46.06)$ & $(45.88)$ & $(35.22)$ & $(40.41)$ \\
Fixed Effects & & & & \\
N & Yes & Yes & Yes & Yes \\
$\mathrm{R}^{2}$ & 278 & 278 & 344 & 318 \\
& 0.121 & 0.123 & 0.131 & 0.135
\end{tabular}

Panel B: Individual days versus simulation

\begin{tabular}{lcccc} 
Event-1 & 82.82 & 85.62 & 90.47 & 93.66 \\
Event- & -109.41 & -104.47 & -104.03 & -146.44 \\
Simulated $p$-value & $0.0060 * * *$ & $0.0092 * * *$ & $0.0064 * * *$ & $0.0003 * * *$ \\
\hline \hline
\end{tabular}




\section{Table 2}

Excluding small firms

This table reports the results of reestimating the Table 1 specifications, using Method 2 risk-adjusted returns by excluding particular subsets of firms from the sample. Row 1 replicates a specification reported by Amihud and Stoyanov (2016); other rows vary the sample exclusion criterion and the treatment definition used.

Three alternative definitions of treatment firms are used. Treat- 1 takes a value of one for firms whose shareholder meetings take place between September and December, Treat-2 takes a value of one for firms whose shareholder meetings take place between July and December, and Treat-3 is identical to Treat-2 but excludes December-meeting firms. In all three definitions, control firms are those whose shareholder meetings take place between January and March. Six-digit Global Industry Classification Standard (GICS) fixed effects are included, and cluster-robust standard errors, clustered at the six-digit GICS level, appear immediately to the right of the coefficient estimates (Treat) in parentheses. The rightmost columns report the individual-event coefficients on the treatment indicator and the likelihood of observing coefficients (simulated $p$-value) at least as large and positive as the observed Event- 1 coefficient and at least as large and negative as the observed Event-2 coefficient. Simulated $p$-values, reported in the rightmost column, are computed using a simulated bivariate null distribution of coefficients generated from all unique pairs of nonevent trading dates from January 2 to June 30, 2010. In the table, "Mcap" refers to market capitalization and "OTC" refers to over-the-counter. Levels of significance are indicated by $*, * *$, and $* * *$, signifying $10 \%, 5 \%$, and $1 \%$, respectively. 


\begin{tabular}{|c|c|c|c|c|c|c|c|c|}
\hline Row & Excluding & $\begin{array}{c}\text { Treated } \\
\text { firm } \\
\text { definition }\end{array}$ & $\mathbf{N}$ & Treat (stan & dard error) & Event-1 & Event-2 & $\begin{array}{l}\text { Simulation } \\
p \text {-value }\end{array}$ \\
\hline 1 & \multirow{3}{*}{ Mcap $<\$ 10$ million } & Treat-1 & 264 & 46.894 & $(42.04)$ & 63.21 & -30.58 & $0.0577^{*}$ \\
\hline 2 & & Treat-2 & 330 & $65.964 * *$ & (25.28) & 79.42 & -52.51 & $0.0217 * *$ \\
\hline 3 & & Treat-3 & 308 & $73.727 * *$ & $(29.24)$ & 77.24 & -70.21 & $0.0180 * *$ \\
\hline 4 & \multirow{3}{*}{ Mcap $<\$ 500$ million } & Treat-1 & 142 & $99.471^{*}$ & (53.94) & 130.25 & -84.26 & $0.0139 * *$ \\
\hline 5 & & Treat-2 & 164 & $98.793^{*}$ & $(50.46)$ & 84.41 & -120.29 & $0.0085^{* * *}$ \\
\hline 6 & & Treat-3 & 156 & $109.529 *$ & $(54.04)$ & 82.73 & -143.34 & $0.0037 * * *$ \\
\hline 7 & \multirow{3}{*}{ Mcap $<\$ 1$ billion } & Treat-1 & 97 & $136.581^{* *}$ & $(59.27)$ & 159.94 & -112.09 & $0.0049 * * *$ \\
\hline 8 & & Treat-2 & 115 & $135.666^{* *}$ & $(52.38)$ & 106.18 & -166.54 & $0.0036 * * *$ \\
\hline 9 & & Treat-3 & 109 & $148.098 * *$ & $(56.03)$ & 101.98 & -197.15 & $0.0031 * * *$ \\
\hline 10 & \multirow{3}{*}{ Mcap $<\$ 10$ million and top and bottom $1 \%$} & Treat-1 & 260 & $68.991 *$ & (36.92) & 93.53 & -44.41 & $0.0216^{* *}$ \\
\hline 11 & & Treat-2 & 323 & $77.872 * *$ & $(30.92)$ & 70.58 & -83.82 & $0.0120 * *$ \\
\hline 12 & & Treat-3 & 302 & $81.889 * *$ & $(31.67)$ & 59.70 & -101.40 & $0.0103 * *$ \\
\hline 13 & \multirow{3}{*}{$\begin{array}{c}\text { Mcap }<\$ 10 \text { million, OTC, penny, and top and } \\
\text { bottom } 1 \%\end{array}$} & Treat-1 & 256 & $68.604 *$ & (37.87) & 93.23 & -44.23 & $0.0216^{* *}$ \\
\hline 14 & & Treat-2 & 315 & $82.546^{* *}$ & (34.08) & 80.26 & -86.37 & $0.0091 * * *$ \\
\hline 15 & & Treat-3 & 294 & $87.058^{* *}$ & $(35.11)$ & 69.69 & -104.92 & $0.0067 * * *$ \\
\hline 16 & \multirow{3}{*}{$\begin{array}{c}\text { Mcap }<\$ 500 \text { million, OTC, penny, and top and } \\
\text { bottom } 1 \%\end{array}$} & Treat-1 & 141 & $99.400 *$ & $(54.10)$ & 130.25 & -84.26 & $0.0139 * *$ \\
\hline 17 & & Treat-2 & 163 & $98.781^{*}$ & (50.58) & 84.41 & -120.29 & $0.0085^{* * *}$ \\
\hline 18 & & Treat-3 & 155 & $109.524^{*}$ & (54.18) & 82.73 & -143.34 & $0.0037 * * *$ \\
\hline 19 & \multirow{3}{*}{$\begin{array}{c}\text { Mcap }<\$ 1 \text { billion, OTC, Penny, and top and } \\
\text { bottom } 1 \%\end{array}$} & Treat-1 & 96 & $136.917 * *$ & $(59.28)$ & 159.94 & -112.09 & $0.0049 * * *$ \\
\hline 20 & & Treat-2 & 114 & $135.782 * *$ & (52.48) & 106.18 & -166.54 & $0.0036^{* * *}$ \\
\hline 21 & & Treat-3 & 108 & $148.255^{* *}$ & $(56.15)$ & 101.98 & -197.15 & $0.0031 * * *$ \\
\hline
\end{tabular}




\section{Table 3}

Excluding particular observations

This table reports the results of reestimating the specifications of Table 1 using Method 2 risk-adjusted returns by excluding particular observations of firms from the sample. Rows 1, 4, and 13 replicate specifications reported by Amihud and Stoyanov (2016), and other rows vary the sample exclusion criterion and the treatment definition used.

Three alternative definitions of treatment firms are used. Treat- 1 takes a value of one for firms whose shareholder meetings take place between September and December, Treat-2 takes a value of one for firms whose shareholder meetings take place between July and December, and Treat-3 is identical to Treat-2 but excludes December-meeting firms. In all three definitions, control firms are those whose shareholder meetings take place between January and March. Six-digit Global Industry Classification Standard (GICS) fixed effects are included, and cluster-robust standard errors, clustered at the six-digit GICS level, appear immediately to the right of the coefficient estimates (Treat) in parentheses. The rightmost three columns report the individual-event coefficients on the treatment indicator and the likelihood of observing coefficients (simulated $p$-value) at least as large and positive as the observed Event- 1 coefficient and at least as large and negative as the observed Event-2 coefficient. Simulated $p$-values, reported in the rightmost column, are computed using a simulated bivariate null distribution of coefficients generated from all unique pairs of nonevent trading dates from January 2 to June 30, 2010. In the table, "M\&A" refers to mergers and acquisitions; "ASB" refers to AdvanSource Biomaterials Corporation; "EONC" refers to eOn Communications Corporation; and "ARG" refers to Airgas, Inc. Levels of significance are indicated by *, **, and $* * *$, signifying $10 \%, 5 \%$, and $1 \%$, respectively. 


\begin{tabular}{|c|c|c|c|c|c|c|c|c|}
\hline Row & Excluding & $\begin{array}{c}\text { Treated } \\
\text { firm } \\
\text { definition }\end{array}$ & $\mathbf{N}$ & Treat (stanc & ard error) & Event-1 & Event-2 & $\begin{array}{l}\text { Simulation } \\
p \text {-value }\end{array}$ \\
\hline 1 & \multirow{3}{*}{ M\&A firms } & Treat-1 & 274 & $94.754^{*}$ & $(53.39)$ & 85.66 & -103.85 & $0.0092 * * *$ \\
\hline 2 & & Treat-2 & 340 & $97.270 * * *$ & (31.28) & 90.64 & -103.90 & $0.0064 * * *$ \\
\hline 3 & & Treat-3 & 314 & $120.122 * * *$ & $(36.66)$ & 93.82 & -146.42 & $0.0003 * * *$ \\
\hline 4 & \multirow{2}{*}{ ASB } & Treat-1 & 276 & 75.860 & (48.07) & 85.76 & -65.96 & $0.0139 * *$ \\
\hline 6 & & Treat-3 & 316 & $106.087 * * *$ & $(35.29)$ & 93.32 & -118.85 & $0.0036^{* * * *}$ \\
\hline 7 & \multirow{3}{*}{ ASB and EONC } & Treat-1 & 274 & $86.604^{*}$ & $(51.20)$ & 89.97 & -83.23 & $0.0096 * * *$ \\
\hline 8 & & Treat-2 & 340 & $92.376 * * *$ & (31.99) & 92.44 & -92.31 & $0.0087 * * *$ \\
\hline 9 & & Treat-3 & 316 & $106.087 * * *$ & $(35.29)$ & 93.32 & -118.85 & $0.0036 * * *$ \\
\hline 10 & ASB and top and bottom $1 \%$ & Treat-1 & 270 & $100.094 * *$ & $(45.76)$ & 102.82 & -89.94 & $0.0057 * * *$ \\
\hline 14 & \multirow[t]{2}{*}{ ARG } & Treat-2 & 342 & $88.513 * *$ & $(33.24)$ & 85.00 & -92.03 & $0.0087 * * *$ \\
\hline 15 & & Treat-3 & 316 & $111.240 * * *$ & $(39.20)$ & 87.97 & -134.50 & $0.0021 * * *$ \\
\hline 16 & \multirow{3}{*}{ ARG and top and bottom $1 \%$} & Treat-1 & 268 & $88.486^{*}$ & $(48.40)$ & 95.91 & -73.37 & $0.0083 * * *$ \\
\hline 17 & & Treat-2 & 330 & $83.625^{* *}$ & $(36.05)$ & 72.39 & -93.88 & $0.0097 * * *$ \\
\hline 18 & & Treat-3 & 308 & $108.574 * *$ & $(43.39)$ & 80.56 & -131.70 & $0.0047 * * *$ \\
\hline
\end{tabular}




\section{Table 4}

Industry fixed effects

This table reports the results of re-estimating the specifications of Table 1 using Method 2 risk-adjusted returns by implementing four-digit Global Industry Classification Standard (GICS-4) fixed effects (Rows 1-3) or by excluding industry fixed effects (Rows 4-6). Row 1 replicates a specification reported by Amihud and Stoyanov (2016); other rows provide alternative specifications.

Three alternative definitions of treatment firms are used. Treat- 1 takes a value of one for firms whose shareholder meetings take place between September and December, Treat-2 takes on the value of one for firms whose shareholder meetings take place between July and December, and Treat-3 is identical to Treat-2 but excludes December-meeting firms. In all three definitions, control firms are those whose shareholder meetings take place between January and March. Cluster-robust standard errors, clustered at the four-digit and six-digit GICS levels for the GICS-4 and no fixed effects specifications, respectively, appear immediately to the right of the coefficient estimates (Treat) in parentheses. The rightmost three columns report the individual-event coefficients on the treatment indicator and the likelihood of observing coefficients (simulated $p$-value) at least as large and positive as the observed Event- 1 coefficient and at least as large and negative as the observed Event- 2 coefficient. Simulated $p$-values, reported in the rightmost column, are computed using a simulated bivariate null distribution of coefficients generated from all unique pairs of nonevent trading dates from January 2 to June 30, 2010. Levels of significance are indicated by *, **, and ***, signifying $10 \%$, 5\%, and $1 \%$, respectively.

\begin{tabular}{|c|c|c|c|c|c|c|c|c|}
\hline Row & Industry fixed effects & $\begin{array}{c}\text { Treated } \\
\text { firm } \\
\text { definition }\end{array}$ & $\mathbf{N}$ & Treat (stand & rd error) & Event-1 & Event-2 & $\begin{array}{l}\text { Simulation } \\
p \text {-value }\end{array}$ \\
\hline 1 & \multirow{3}{*}{ GICS-4 } & Treat-1 & 278 & 76.876 & $(58.86)$ & 72.19 & -81.56 & $0.0151^{* *}$ \\
\hline 2 & & Treat-2 & 344 & $90.607 *$ & $(43.59)$ & 87.05 & -94.16 & $0.0068 * * *$ \\
\hline 3 & & Treat-3 & 318 & $112.628 * *$ & $(49.47)$ & 91.97 & -133.29 & $0.0003 * * *$ \\
\hline 4 & \multirow{2}{*}{ No fixed effects } & Treat-1 & 278 & $71.822 *$ & $(42.10)$ & 59.27 & -84.38 & $0.0279 * *$ \\
\hline 6 & & Treat-3 & 318 & $110.718 * * *$ & $(28.74)$ & 81.35 & -140.08 & $0.0003 * * *$ \\
\hline 7 & \multirow{3}{*}{ GICS-4, exclude top and bottom $1 \%$} & Treat-1 & 270 & 73.744 & $(49.41)$ & 86.14 & -57.59 & $0.0152 * *$ \\
\hline 8 & & Treat-2 & 332 & $71.296^{* *}$ & $(32.72)$ & 64.19 & -78.14 & $0.0169 * *$ \\
\hline 9 & & Treat-3 & 310 & $91.753 * *$ & $(40.10)$ & 72.00 & -111.32 & $0.0011 * * *$ \\
\hline 10 & No fixed effects, exclude top and bottom $1 \%$ & Treat-1 & 270 & $63.922 *$ & $(33.49)$ & 67.94 & -59.91 & $0.0292 * *$ \\
\hline
\end{tabular}

